\title{
Application of 3D Printing in Education
}

\author{
Mr. Shrinath S Pai, \\ Research Scholar, \\ Jain University, \\ Bangalore \\ India
}

\author{
Mr. Gourish B, \\ Asst Professor, \\ Dept of Computer, \\ Shree Guru \\ Sudhindra BCA \\ College, Bhatkal \\ India
}

\author{
Ms. Pallavi Moger, \\ Student, Dept of CS, \\ Shree Guru \\ Sudhindra BCA \\ College, Bhatkal \\ India
}

\author{
Mr. Pavan Mahale, \\ Student, Dept of CS, \\ Shree Guru \\ Sudhindra BCA \\ College, Bhatkal \\ India
}

\begin{abstract}
This paper provides a review of literature concerning the application of 3D printing in the education system. The review identifies that 3D Printing is being applied across the Educational levels [1] as well as in Libraries, Laboratories, and Distance education systems. The review also finds that 3D Printing is being used to teach both students and trainers about 3D Printing and to develop 3D Printing skills.
\end{abstract}

Keywords: Education, 3DP, Education Application, School, Design

\section{INTRODUCTION}

3D Printing is a process for making a physical object from a three-dimensional digital model, typically by laying down many successive thin layers of a material. [2] It brings a digital object (its CAD representation) into its physical form by adding layer by layer of materials.

Even though 3D printers have been around for almost 30 years, the recent rise of low-cost printers has led some to proclaim the onset of a new industrial revolution. Schools and libraries all over the world are bringing these powerful tools to students in classrooms. [3]

For example, China is putting 3D printers in each of its 400,000 elementary schools. In the U.S., we are adding 3D printers into schools at a good rate, particularly into CAD programs, but also into traditional art and social studies classrooms and even business programs.

The result of bringing these tools into classrooms is a rekindling of the powerful pedagogy of hands-on learning, which was prevalent in American schools mid-twentieth century. As we will demonstrate, 3D printing leverages handson learning to deepen our educational approach to traditional academic subjects.

\section{OVERVIEW / HISTORY}

Although $3 \mathrm{D}$ printing is commonly thought of as a new 'futuristic' concept [4], it has actually been around for more than 30 years.

The earliest 3D printing technologies first became visible in the late 1980's, at which time they were called Rapid Prototyping (RP) technologies. This is because the processes were originally conceived as a fast and more cost-effective method for creating prototypes for product development within industry.

3D Systems' first commercial RP system, the SLA-1, was introduced in 1987 and following rigorous testing the first of these system was sold in 1988 .
Throughout the 1990's and early 2000's a host of new technologies continued to be introduced.

In 2007 , the market saw the first system under $\$ 10,000$ from 3D Systems, but this never quite hit the mark that it was supposed to.

2012 was the year that alternative 3D printing processes were introduced at the entry level of the market.

$3 \mathrm{D}$ printer sales have been growing ever since, and as additive manufacturing patents continue to expire, more innovations can be expected in the years to come.

3D Printing essentially describes a assortment of technologies that digitally formulate three dimensional objects on a preservative layer-by-layer basis. Its official classification of "additive manufacturing" (AM) is defined as "a process of joining materials to make objects from 3D model data, usually layer upon layer, as opposed to subtractive manufacturing methodologies". [5]

3D Printing possesses a number of advantages relative to these processes. However, as an emerging technology, it is still in development; it has yet to fully realise its full performance and there are additional socioeconomic challenges to overcome based on the novelty of the technology.

The explosion in consumer 3D Printing originated with the RepRap project, an open source project to create a selfreplicating robot. This project attracted significant interest globally from members of the Maker movement. The combination of this project and the rise of crowd funding platforms such as Kick starter and Indiego go has enabled numerous entrepreneurial ventures to launch onto the market.

\section{3D PRINTING}

3D printers build objects using a process known as additive manufacturing. Material is put down in layers; each 
layer adds to the previous layer and in turn becomes a base for the next layer. [6]

Most 3D printers in the consumer market use thermoplastic inks in the printing process. These polymers become soft and pliable within a temperature range and then re-solidify when allowed to cool.

Typical manufacturing techniques are known as 'Subtractive Manufacturing' such as Milling and Cutting. This type of process creates a lot of waste since; the material that is cut off generally cannot be used for anything else and is simply sent out as scrap.

3D Printing eliminates such waste since the material is placed in the location that it is needed only, the rest will be left out as empty space.

\section{3D Printing Application Areas}

3-D printing is extremely enlarging its application areas. The capabilities of this 3 dimensional technology are growing rapidly with the market demands. Today, this technology has become a possible alternative to conventional manufacturing processes [7] in an increasing number of applications including engineering, automotive, medical, education, fashion and many more. The advantages of 3-D printing over traditional manufacturing methods have changed the way; many things are designed, developed, produced and tested.

3D Printing is currently used in following areas:

- $\quad$ Engineering

- Medical Sector

- Fashion Industry

- Landscaping \& Sculpturing Services

- Education, Research \& Development

- Automobile Engineering

- Aeronautical Engineering

- Robotics

- Construction Industry

- Environmental Conservation

- Specialty Materials

- 3D Bioprinting

- Bio-Organ printing

- Health Sector

- Dental implants

- $\quad$ Skull and jaw implants

- Security and integration

\section{3D Printing Application in Education}

3D printing technology is a rising technology in universities, colleges and high schools. With this technology, teaching and learning process has changed drastically.[8] 3 dimensional printing is a revolutionary and innovative technology that brings with itself, new methods of learning and understanding concepts that were very difficult with the traditional methods.

3D Printing is widely used in Education Sector.
Chemistry: 3D Structures, Molecules, Organic Bonding,

Elements construction

Mathematics: Create geometrical objects, shapes presentation.

Marketing: Sample Display Product, Chart, 3D Graphs

Sports Education: Blueprint of sports / games plan, Sample sports equipments.

Fashion Technology: Dress Material Design,

Pre-Schools: Training objects, Teaching Aids

Networking: Network Topology Design, Network

Components Design

Aeronautical: Aerodynamics design, Solid Objects

Music Training: Musical Instrument Design (Demo)

Architecture: Building Design, Blueprint

History: Historical Object Design, Fossil \& Monuments Design,

Food Technology: Food Sample Design, Food Making

Graphic Design: Design on 3D Objects, Learning Tools

Geography: Models, Map Design

Engineering: Drawing, Production Unit Sample Design

Biology: Cell Structure, Specimens

\section{Advantages of 3D printers in Education, Research \& Development:- [9]}

- It gives the practical exposure to the participants.

- The blueprint of the object helps in understanding the real object.

- Students of architecture, fine arts or biomedicine can benefit from this state-of-the-art printing technology

- This 3D printing technology gives the students complete understanding of objects and structures

- Prototype design helps students in understanding subject.

- Students can give their digital data a physical appearance with this technology

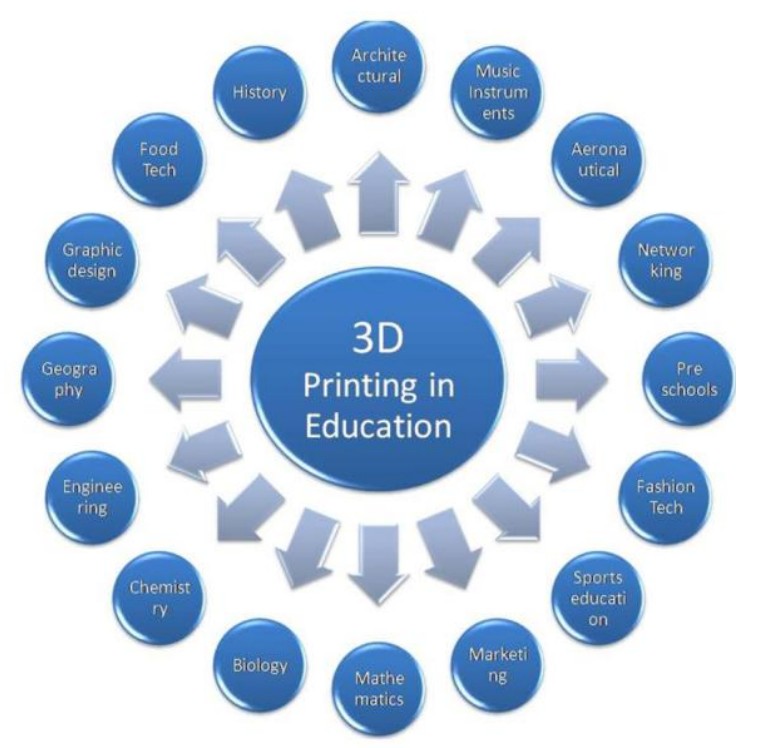




\section{Conclusion}

$3 \mathrm{D}$ printing technology is a rising technology in universities, colleges and high schools. With this technology,

\section{REFERENCES}

[1] Simon Ford, Tim Minshall, 2016. 3D Printing in education: a literature review, version 1.0 .

[2] Igor Verner, Amir M, Digital Design and 3D Printing in technology teacher education, Procedia CIRP 36 ( 2015) 182-186.

[3] School News, The 3D Printing Revolution in Eucation, A new approach to learning in the $21^{\text {st }}$ century.

[4] Kainant W, Hasnain A, Ovais H, Innovation in Education - Inclusion of 3D-Printing technology in Modern Education system, ISSN 2222-1735, Vol 8, No 1, 2017

[5] Alekos Pantazis, Christina Priavolou, 3D printing as a means of learning and communication: The 3Ducation project revisited, www.elsevier.com/locate/tele.

[6] Vasilis K, Vasilis N, Christos G, Open source 3D printing as a means of learning: An educational experiment in two high schools in Greece, Telematics and Informatics 32 (2015) $118-128$

[7] Jennifer Loy, eLearning and eMaking: 3D Printing Blurring the Digital and the Physical, Educ. Sci. 2014, 4, 108121; doi:10.3390/educsci4010108

[8] David Barlex, Making by printing - disruption inside and outside school?

[9] 3D Printer, Buyer's Guide, For Professional and Production Applications teaching and learning process has changed drastically. 3 dimensional printing is a revolutionary 